História (São Paulo)

\title{
Pueblos y Paisajes en la Royal Society de LondresLas ciencias humanas y el imperialismo británico $(1860-1918)$
}

\section{Pessoas e Paisagens na Royal Society de Londres. As Ciências Humanas e o imperialismo britânico (1860-1918)}

\section{People and Landscapes in the Royal Society of London Social Sciences and British imperialism (1860-1918)}

Claudio Llanos REYES*

Resumen: El objetivo de este trabajo es conocer la forma en que sectores intelectuales de las ciencias humanas insertos en la Sociedad Real de Londres justificaron la expansión imperialista británica, mediante el desarrollo de un conjunto de representaciones sobre sociedades, espacios y culturas, entre 1860 y 1918.

El principal supuesto de este trabajo es que el proceso de expansión territorial y de influencia del imperialismo colonial británico se vio legitimado desde sectores de la sociedad científica británica, que construyó un corpus teórico y una forma de ver al no europeo, que asentada sobre los valores científicos positivistas, buscó justificar y explicar el dominio británico sobre otras tierras, sociedades y culturas.

Palabras claves: Imperialismo. Gran Bretaña. Intelectuales. Sociedad Real de Londres.

Resumo: O objetivo deste estudo foi determinar como setores intelectuais das ciências humanas embutidos na Royal Society of London justificaram a expansão imperialista britânica, desenvolvendo um conjunto de representações das sociedades, os ambientes e culturas, entre 1860 e 1918 . O pressuposto principal deste trabalho é que o processo de expansão territorial e de influência do imperialismo colonial britânico foi legitimado a partir de setores da sociedade científica britânica, que

\footnotetext{
* Doctor en Historia. Profesor de Historia Contemporánea, do Instituto de Historia, Pontificia Universidad Católica de Valparaíso, Chile. Casilla 4059, Valparaíso, Chile. E-mail: claudio.llanos@ucv.cl
} 
Pueblos y Paisajes en la Royal Society de LondresLas ciencias humanas y el imperialismo británico

$(1860-1918)$

construiu um corpo teórico e uma maneira de ver o não-europeu, assentados em valores científicos positivistas, com o objetivo de justificar e explicar o domínio britânico sobre outras terras, sociedades e culturas.

Palavras-chave: Imperialismo. Grã-Bretanha. Intelectuais. Sociedade Real de Londres.

\begin{abstract}
The purpose of this paper is to determine the manner in which British intellectual factions within the Royal Society developed depictions of societies, non-European cultures and territories in order to justify British imperialist expansion, between 1860 and 1918.

The main thesis of this research is that the process of territorial expansion of British colonial imperialism was legitimized by certain sections of British scientific society that built a theoretical corpus to justify and explain British dominion over other lands, societies and cultures.
\end{abstract}

Keywords: Imperialism. Great Britain. Intellectuals. Royal Society of London.

\title{
Introducción
}

El problema que da origen a este trabajo es el de la forma en que los sectores intelectuales insertos en la Sociedad Real de Londres representaron el mundo (sociedades y culturas). Se busca conocer en qué medida estas miradas se ligan a un proceso de legitimización científica del imperialismo británico entre 1860 y 1918 . Así, nos aproximaremos a las relaciones que se dieron entre las construcciones surgidas del campo científico ${ }^{2}$ y las políticas expansionistas del imperialismo británico ${ }^{3}$.

Las fuentes usadas en esta investigación son las revistas publicadas principalmente por la Royal Geographical Society of London y la Antropological Society of London ${ }^{4}$. Estas representan un recurso abundante de materiales que permiten obtener comprensión profunda de las ideas y discusiones desarrolladas en un sector de la intelectualidad y la élite británica.

La relevancia del uso de los artículos y transcripciones de presentaciones y discusiones publicadas por las disciplinas de la sociedad científica británica tiene particular importancia y es un 
aporte, pues han sido materiales que se han usado relativamente poco ${ }^{5}$ en comparación con el desarrollo de las investigaciones en torno al imperialismo cultural que han concentrado sus miradas en la literatura (el canon literario y la literatura de viajes) ${ }^{6}$ y los estudios lingüísticos ${ }^{7}$. En este enriquecedor desarrollo han tenido particular influencia los enfoques postcoloniales de Said, Young, Bhabha, etc.

Para este estudio se ha revisado la casi totalidad de las publicaciones señaladas (dentro del periodo estudiado) y si bien se pueden apreciar diferencias y algunas tendencias divergentes dentro de los campos científicos estudiados, estás no lograban tener una posición dominante dentro la élite intelectual estudiada. Por ello este trabajo se concentra en los lineamientos y nociones más presentes dentro de la sociedad científica del periodo ${ }^{8}$. De esta forma podremos aproximarnos mejor a la forma en que sectores de la elite londinense entendían el mundo en el que vivían y las formas de relación establecidas en él.

Este trabajo se divide en cuatro partes, en las dos primeras “escucharemos” principalmente las representaciones de diversos expositores de la sociedad científica británica. En ellas se verá la mirada sobre los pueblos y los espacios geográficos. En la tercera veremos la relación que se estableció entre principalmente entre la geografía y la antropología y los objetivos “nacionales” de Gran Bretaña en la Primera Guerra Mundial. En la cuarta parte (conclusión) se señala en rasgos generales algunas de las nuevas miradas sobre el imperialismo, como fenómeno, ya no solamente visto algo solamente económico, sino que con dimensiones culturales y científicas que lo constituyeron.

\section{Naturaleza y culturas: el “orden natural” de virtudes y defectos}

El contexto político-social donde se inserta esta investigación cubre casi en su totalidad la llamada época victoriana y dos décadas del reinado de Eduardo VII. Durante el reinado de Victoria el Imperio británico logró un grado de desarrollo e influencia a nivel económico, que hizo de Londres el corazón mundial de los negocios y de una de los más extensos aparatos de administración colonial en el siglo XIX y parte del XX, como apunta Bonnie Smith (2007) “A la muerte de la reina Victoria en enero de 1901, Gran Bretaña reclama gobernar el 25 por ciento de la masa terrestre y 20 por ciento de la población mundial. Su más orgulloso logro era su imperio en India” (SMITH, 2007, p.8).

El desarrollo del imperialismo británico estuvo marcado por una serie de procesos que en diversos niveles tendieron a constituirlo. En lo económico, su existencia está profundamente ligada al 
Pueblos y Paisajes en la Royal Society de LondresLas ciencias humanas y el imperialismo británico

(1860-1918)

desarrollo del capitalismo desde el siglo XIX. A partir de ese siglo la economía capitalista experimentó una transformación mayor en el plano productivo general: la revolución industrial. En lo cultural se observa la consolidación de un conjunto de ideas que intentaron explicar y justificar el poder que las potencias industriales lograron en ese periodo.

Durante el periodo estudiado se puede observar el desarrollo de un conjunto de ideas que acompañaron y justificaron el proceso de expansión del Imperio Británico en particular y de Europa en general. Tal como apunta Turner estas nociones eran difundidas, hechas públicas, por razones y objetivos muy diferentes de los actuales

Los divulgadores científicos no propagaban el conocimiento científico para su propio bien, y su trabajo puede tener poco o nada que ver con la reales motivaciones o los objetivos de la investigación científica. Más bien conscientemente intentan persuadir a los sectores públicos o influyentes para apoyar a la ciencia que contiene valores ampliamente aceptados en lo social, en lo políticos y religioso y que por lo tanto, es digna de recibir la atención del público, estímulo y financiación (TURNER 1980, 590).

Desde la segunda mitad del siglo XIX con los hallazgos en la ciencia y en particular con la visión evolucionista elaborada a partir de Darwin, Huxley, Wallace y sobre todo, de Spencer se desarrolló a nivel científico una visión lineal de la historia que legitimaba a la sociedad capitalista, instalando el proceso recorrido por Europa como la expresión de civilización (FONTANA, 2000, p.121). En este marco, desde la ciencia se generaron ideas que buscaron justificar el orden social e internacional. Así, la mirada desde las ciencias humanas contenía también los intereses de las sociedades donde se desarrollaban. Como ejemplo de esto encontramos ideas expuestas frente a la Anthropological Society of London en 1867,

El principio de que el hombre es el tipo de creación es aplicable tanto a la geografía como la zoología. Las razas en sus centros muestran cualidades en armonía con el entorno climático, botánico, zoológico y geológico. Por lo tanto, el hombre de la localidad es su clave y su epítome. Montañas y ríos por su elevación, curso y dirección, ilustran la historia, de caracteres y las migraciones de las razas como el desierto, estepas, llanos, el carácter nacional o racial y hábitos; por lo tanto, los habitantes de los distritos montañosos son distinguidos por la suavidad del espíritu y el amor por la libertad. Los habitantes de estepas son democráticos, en lugar de aristocrático, cuya tendencia es mirar a jefes como al pico de la montaña. Naciones templadas en pasiones -aquellas bajo el Gobierno moral más estricto residen principalmente en las regiones templadas. La precipitación de países tipifica el grado de las ventajas morales y espirituales ${ }^{9}$.(NAPIER, 1867, p.CLXXVI). 
Así, las presentaciones y artículos de un sector importante de la intelectualidad británica incluían un determinismo entre la geografía y las características no solamente físicas, sino también morales de los pueblos, las culturas, etc. ${ }^{10}$.

Si beauty is in the eyes of who observes, la belleza del mundo fue vista y catalogada a partir de las ideas, prejuicios, esperanzas e intereses de quienes observaban desde Europa. Estas ideas tenían a su favor, el poder, la flota naval, la industria y por cierto la admiración de las elites que les rodeaban.

En el plano económico mundial, los británicos tenían razones para sentirse poderosos, su crecimiento superaba durante el siglo XIX a la de los otros países. Tal como se observa en el cuadro 1 desde mediados del siglo XIX el crecimiento del Producto Interno Bruto (per cápita) fue superior en Gran Bretaña, solamente Estados Unidos lograría dejarla atrás después de la Primera Guerra Mundial. Así, muchos británicos consideraron que su avance y poder económico tenía origen en una superioridad racial, cultural y social.

En este contexto es preciso señalar que el estudio del imperialismo británico no se concentra solamente en mapas coloreados o sus acciones formales, sino que también debe considerar la expansión entre 1812 - 1914 de más de 20 millones de británicos que exploraron, colonizaron y difundieron la modernidad europea (GALLAGHER y ROBINSON 1953, 5).

\section{Cuadro 1}

Crecimiento Británico del PIB en miles de dólares (per cápita) en comparación con 3 países

(Dólares en valor de 1990)

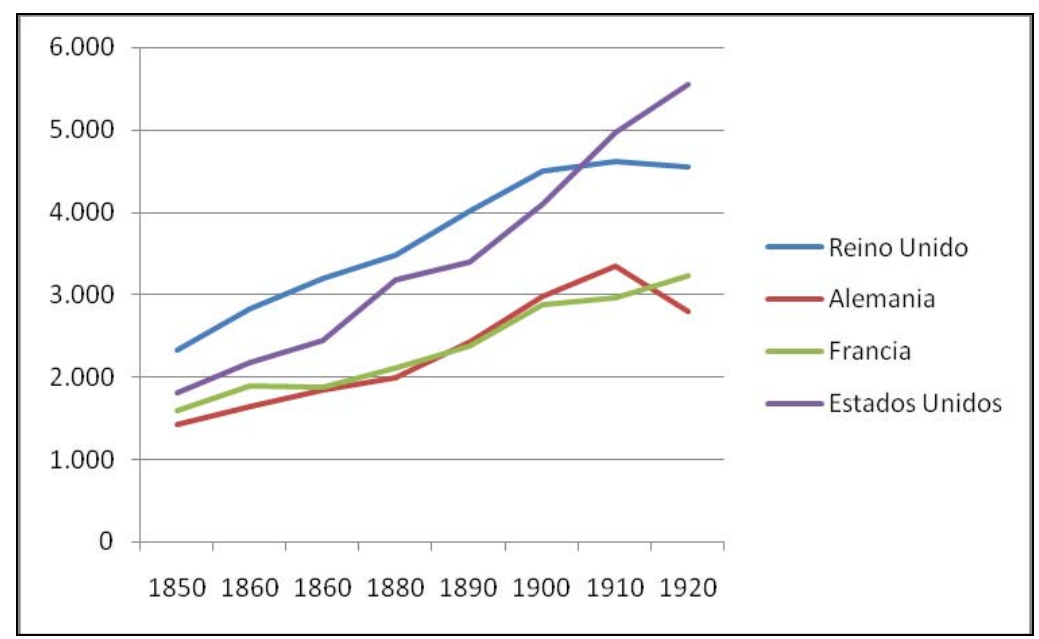

Fuente: Maddison, Agnus, Historical Statistics of the World Economy: 1-2008 AD . http://www.ggdc.net/MADDISON/oriindex.htm

Entre la intelectualidad inglesa de la época victoriana y en términos generales, la aplicación de "la lucha por la supervivencia” y el triunfo de los evolutivamente "superiores” sobre los "inferiores” se 
Pueblos y Paisajes en la Royal Society de LondresLas ciencias humanas y el imperialismo británico

(1860-1918)

puede observar una tradición de pensamiento construida a partir de la ideas de Malthus, Darwin y Spencer y la consolidación del liberalismo como forma de entender las relaciones sociales y el mundo (FREEDEN, 1976). Así, el desarrollo del eje superior-inferior en la historia contemporánea se puede identificar claramente.

La noción de superioridad brindó a las potencias europeas en general un marco explicativo del dominio sobre otras regiones, era como nos apunta Said la expresión cultural del imperialismo que configuraba una ideología capaz de entender el mundo y el “orden” que los diversos pueblos o "razas" tenían en él (SAID, 2001).

La argumentación con eje en la superioridad estaba presente desde antes de la publicación del Origen de las Especies. Desde algunos aspectos del trabajo de Linneo, las observaciones científicas y sus mediciones encontraban "pruebas” de las diferencias en la propia anatomía humana. Así, por un particular derrotero de asociaciones el cráneo y sus formas “constituyó” un testimonio de "poder” o “subordinación”. La inteligencia humana no era considerada un bien general sino que un beneficio distribuido diferenciadamente en las diferentes "razas” y así como el éxito económico era prueba de salvación para los calvinistas, para sectores científicos el éxito en la “domesticación” de la naturaleza (agricultura, comercio, industria, gobierno, etc.) era prueba de una “inteligencia superior”, que tenía su expresión anatómica en la forma del cráneo. Por cierto el cráneo “superior” era el que se encontraba entre los indoeuropeos ${ }^{11}$.

La noción de superioridad presente entre la elite inglesa y británica en su relación con el “mundo” fue en cierta medida expresión y expansión de su relación con el conjunto social inmediato de una Inglaterra que experimentaba una profunda transformación social, donde el surgimiento de nuevas clases sociales asociadas a la industrialización alteraba la confianza que los sectores de elite tenían en el status quo. La manera de entender al proletariado, al trabajador industrial estaba marcada por la desconfianza, era visto como un “bárbaro” dentro de la “civilización”. Así se podía justificar no solo la represión que defendía la “civilización” sino que también la miseria en la que vivían.

Una suerte de humo negro cubre la ciudad. El sol que vemos a través de él es un disco sin rayos [...] Mil ruidos perturban este laberinto húmedo y oscuro [...] Desde esta sucia alcantarilla fluye un vasto caudal de industria humana que fertiliza el mundo entero. Desde este inmundo sumidero fluye oro puro. Aquí la humanidad alcanza su desarrollo más completo y su extremo más brutal: aquí la civilización obra su milagro, y el hombre civilizado vuelve a ser un salvaje. (TOCQUEVILLE, 1835 apud NEWSOME, 2001, p.35). 
En 1834 la Poor Law Amendment Act expresó la decisión de terminar con la asistencia a los pobres que no aceptaran los trabajos ofrecidos, en su mayoría en workhouse, que eran asilos donde trabajaban por comida y techo (Newsome, 2001, p.30-35). Charles Dickens uno de los varios que constituyó la novela social, nos ha dejado varios testimonios de los sufrimientos y las condiciones de vida de estas "masas” que habitaban las ciudades industriales y que desde los sucesos de Perterloo generaban las peores pesadillas entre miembros de la aristocracia ${ }^{12}$.

Cuando un extraño atraviesa las masas de seres humanos que se han aglomerado alrededor de las hilanderías y estampaciones...no puede contemplar esas 'atestadas colmenas’ sin sentimientos de ansiedad y aprensión que llegan a consternarle. La población, como sistema al que pertenece, es nueva; pero está creciendo por momentos en extensión y fuerza. Es un agregado de multitudes que nuestras ideas expresan con términos que sugieren algo amenazador y pavoroso [...]. (TAYLOR, 1842 apud THOMPSON, 2001, p.21).

En este punto es inevitable referirse al trabajo de Darwin (publicado en 1859), en su propio contexto histórico, social e ideológico. No desde la perspectiva de su argumentación biológica - que no es nuestro terreno- sino que considerando el impacto que tuvo para la constitución de un eje ideológico de relaciones superior-inferior con el que desde Europa importantes sectores de las elites escrutaban el mundo y preparaban su reparto.

Ligado a las ideas de Darwin o a la interpretación de estas se estableció el Darwinismo Social. Sobre éste y la relación del propio Darwin con una aplicación socioeconómica de la "teoría de la evolución”, se ha discutido bastante y de seguro seguirá siendo un tema de debate que supera los límites de este trabajo. Aún así se puede considerar que la adaptación y uso del descubrimiento de Darwin en un discurso de superioridad racial constituye un fenómeno tanto de continuidad en cuanto el sostenimiento y defensa de relaciones de poder, como además de rompimiento con las tradiciones más radicales e igualitarias de la ilustración.

Si bien las ideas de "superioridad” de unos sobre otros son observables en momentos anteriores, las características particulares de la nuevas construcciones - que las hacen nuevas e identificables - son el arsenal “científico” en el que se apoyan (en una época donde la ciencia se erigía como nunca antes), en la extensión de las observaciones y en la transformación mundial a la que están asociadas: la revolución industrial y el imperialismo contemporáneo o moderno.

En siglo XIX las ideas que se desarrollaban sobre la humanidad se tendieron a establecer niveles de “superioridad”, de “civilización”, de “dominio”, etc. Estos planteos revisaron la imagen de la 
Pueblos y Paisajes en la Royal Society de LondresLas ciencias humanas y el imperialismo británico

(1860-1918)

humanidad "igual” planteada por sectores del pensamiento ilustrado. En este marco las diferencias culturales y de adaptación a la naturaleza fueron presentadas como evidencias del "salvajismo", la “inmoralidad”, etc., de los pueblos no europeos presentándose en muchos casos como evidencia de “animalidad”.

En este contexto, en 1867 G. Nappier publicó las siguientes (gráficos 2 y 3) tablas de las “razas humanas”13. En ellas las categorías incluían “razas” intelectuales, morales, las con pocas iniciativa, etc. Por cierto que dentro de las más “desarrolladas” en lo intelectual y moral se encontraban los griegos, eslavos, etc., y en la subdivisión "moral-intelectual” se encontraban los sajones, escandinavos y las "tribus teutónicas".

Cuadro 2 y 3: “Table of Human Races, Classed in Accordance with the Moral and Intellectual Characteristics”.

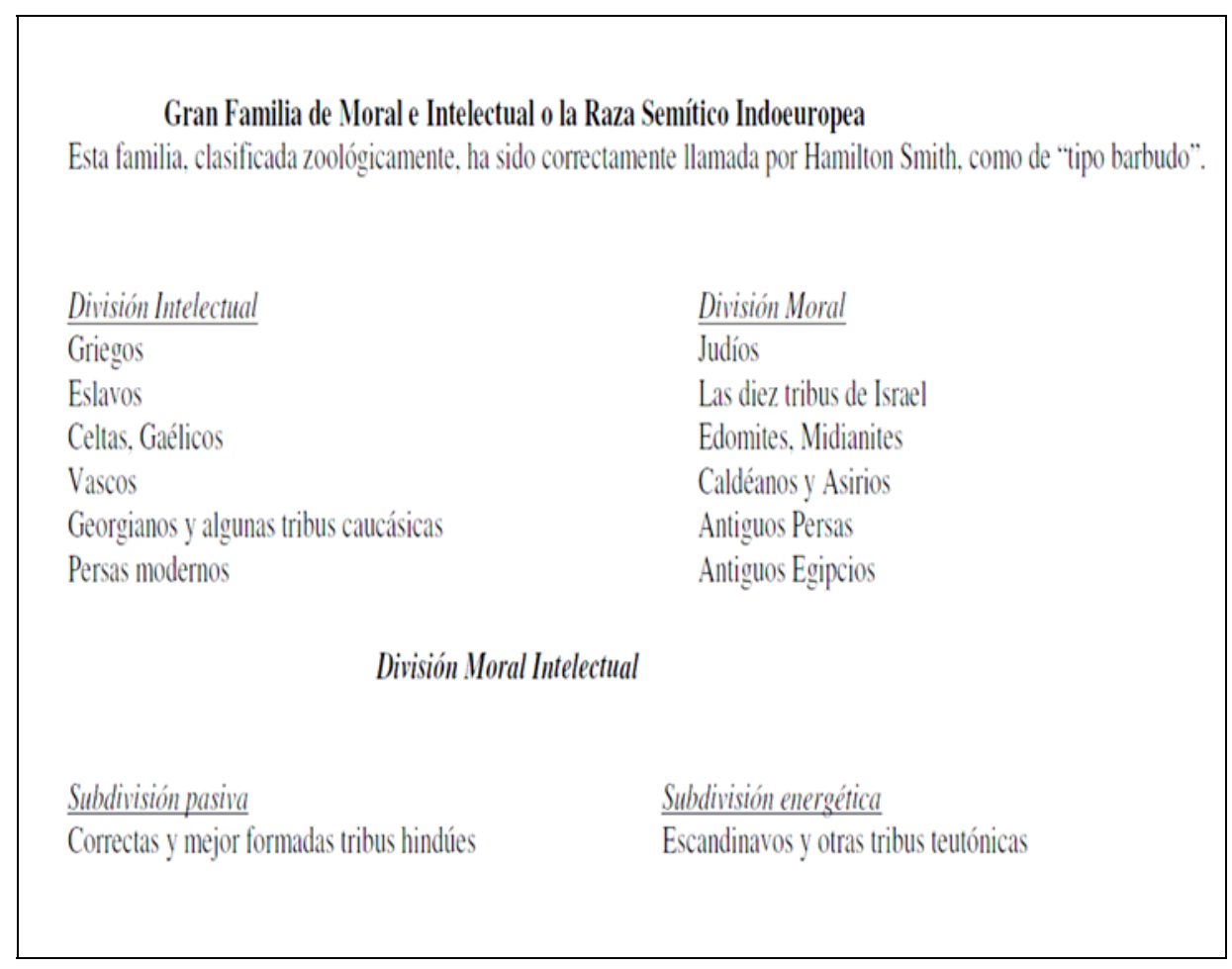

História (São Paulo) v.30, n.1, p.306-331, jan/jun 2011 ISSN 1980-4369 313 


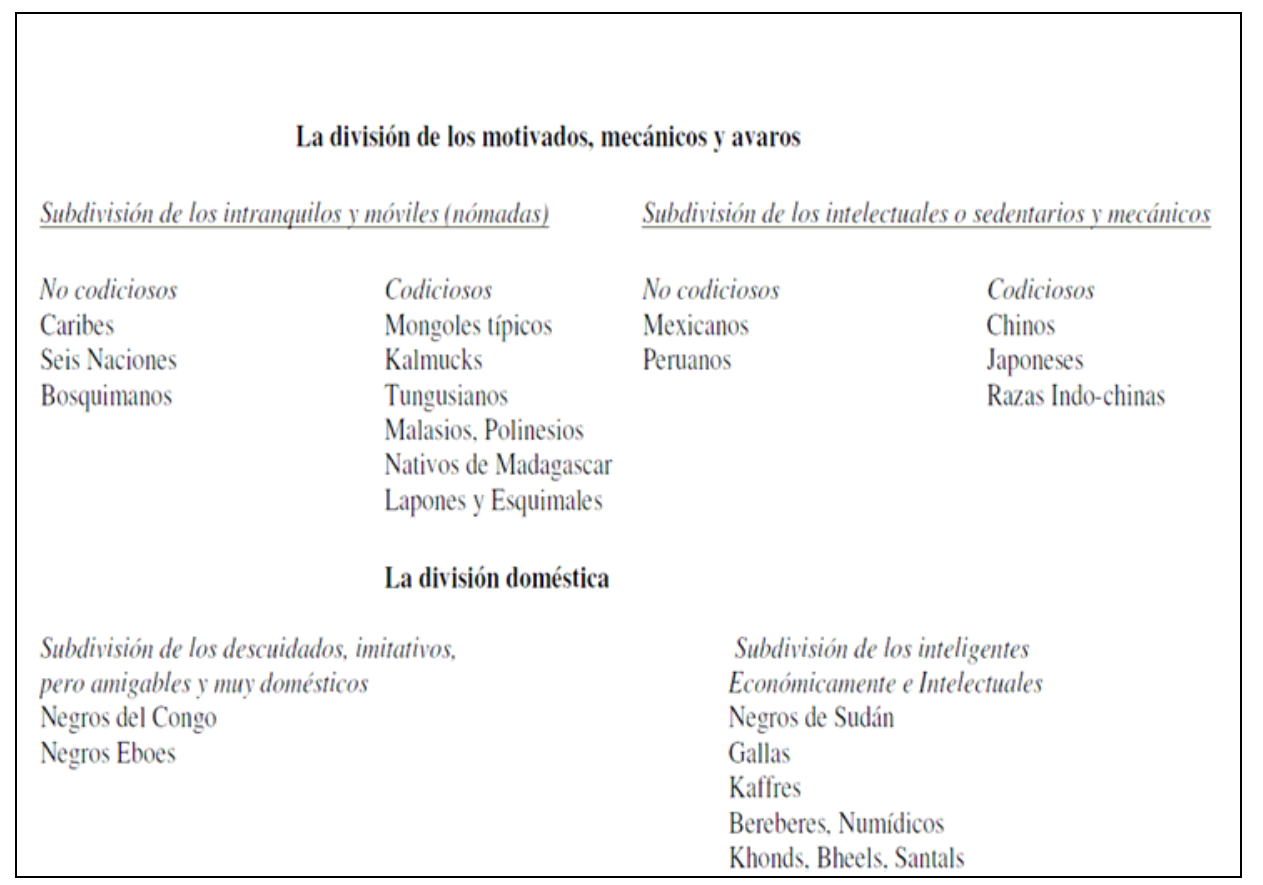

Fuente: Nappier, G. “Table of Human Races, Classed in Accordance with the Moral and Intellectual Characteristics”. En: Anthropological Society of London, Vol. 5, 1867.

Desde Londres la mirada sobre los aborígenes australianos y de las islas Andamares, los colocaba en uno de los niveles “inferiores” de la humanidad: a "pueblos sin historia”, "sin conquistas”, donde las formas particulares de vida, las adaptaciones distintas al medio natural eran vistas no sólo con curiosidad sino que además con asombro y disgusto. Por cierto que observar otras formas de alimentación debe de haber causado algunas sensaciones negativas en los viajeros británicos o en los lectores de sus relatos. Y las diferencias en las formas de actuar frente a la muerte, la pasión y las demostraciones de dolor fueron vistas con el “decoroso” ojo del burgués ${ }^{14}$.

Tomemos la imagen de Sir George Grey sobre un australiano: 'en total un espectáculo repugnante, saliendo de una ballena podrida, temperamental, violento, que se frota desde la cabeza hasta los pies con aceite apestando, lleno hasta el hastío con carne pútrida y sufriendo trastornos cutáneos provocados por la mucha alimentación'. O tomado la imagen de Andamaners muertos del Dr. Moutt 'Su expresión tal como la había dejado la visita de la muerte fue verdaderamente repulsiva y aterradora. Sus características distorsionadas por las pasiones más violentas fueron demasiado horribles para los moldes humanos, y podría considerarse sólo como los tipos de los demonios más feroces y implacables. Su aspecto era realmente de demonio. Dudo si Fuseli representando las pasiones peores y más violentas de la humanidad jamás haya imaginado nada tan horrible como las imágenes que nosotros ahora vemos'. Ignorantes, brutos, de desnudez total y de relaciones sexuales promiscuas, dan una noción de su condición moral [...]. Leer una tal descripción de la vida salvaje es leer todas; en 
Pueblos y Paisajes en la Royal Society de LondresLas ciencias humanas y el imperialismo británico

$(1860-1918)$

resumen, el salvaje es no una señorial, libre, noble criatura, presentando el espectáculo feliz de inocencia poco sofisticada y libertad primitiva, pero generalmente un miserable depravado, horrible y sanguinario; su cuerpo igualmente desagradable para el ojo y la nariz y su existencia grotesca dividida entre una desconfianza de la vida, una desconfianza aún mayor de la muerte, que él sueña como fuego. Son, dice el Sr. Darwin, quien, a diferencia de la compañía entera de quienes han idealizado acerca de ellos, ha tenido la oportunidad de inspeccionarles personalmente 'son hombres cuyos signos y expresiones son menos inteligibles para nosotros que los de los animales domesticados; [...] no poseen el instinto de los animales, pero todavía parecen presumir de la razón humana, o al menos de actúa como consecuencia de ello. [...]'. Si cabe preguntarse qué es la historia de estas razas, la respuesta es muy sencilla. Ellos no tienen antecedentes. No ha originado un descubrimiento único, no han promulgado un pensamiento único; no han establecido una única institución. (FARRAR, 1867, p. 118119).

Los pueblos "sin historia” constituyeron una forma de entender a las sociedades no europeas. En esta lógica la entrada en la "historia”, es decir en el orden "civilizado" se daba en la medida que se vinculaban con la expansión y los intereses imperiales en desarrollo.

La mantención de nociones de superioridad racial es patente en la segunda mitad del siglo XIX. Las preocupaciones de los hombres de ciencia e imperio parecen haber estado marcadas por el marco de mundialización económica y de intercambios comerciales y financieros, pues el intereses por proteger de la “degeneración” racial a los “humanos superiores” vía cruzamiento racial parece haber sido la forma de restringir el “intercambio” a lo meramente económico.

La Unión de la más alta y más baja de las razas humanas da una progenie intermedia, inferior a la primera y superior a la última. La descendencia de un escandinavo y un negro es inferior a la escandinava y superior a la negra. La descendencia de un inglés y un australiano, se degrada el inglés y algo mejora el australiano: el mestizo es muy inferior a la español, pero muy superior al indio piel roja. (CRAWFURD, 1861, p.356).

Por cierto que la “degradación” racial no ocurría si la “mezcla” se daba dentro de sociedades cercanas o aledañas como las que ocupaban el continente europeo,

La unión de espacies cercanas de las raza humana no produce cambios apreciables en sus descendientes. Esto es aplicable a todas las diferentes razas de la familia europea El pueblo de Italia no ha sufrido degradación de su larga mezcla de sangre griega y teutónica; tampoco los habitantes de Francia, con su mezcla de sangre italiana o alemana [...]. (CRAWFURD, 1861, p.356).

Una de las preocupaciones latentes en el siglo XIX a nivel de las potencias europeas fue la ocupación de los espacios que estaban más allá de sus fronteras, particularmente en África, Asía y 
América Latina. Esta ocupación podría ser directa en el caso del establecimiento de una administración colonial directa como el caso de la India o el África o bajo una relación más informal como en el caso de América Latina (YOUNG, 2001).

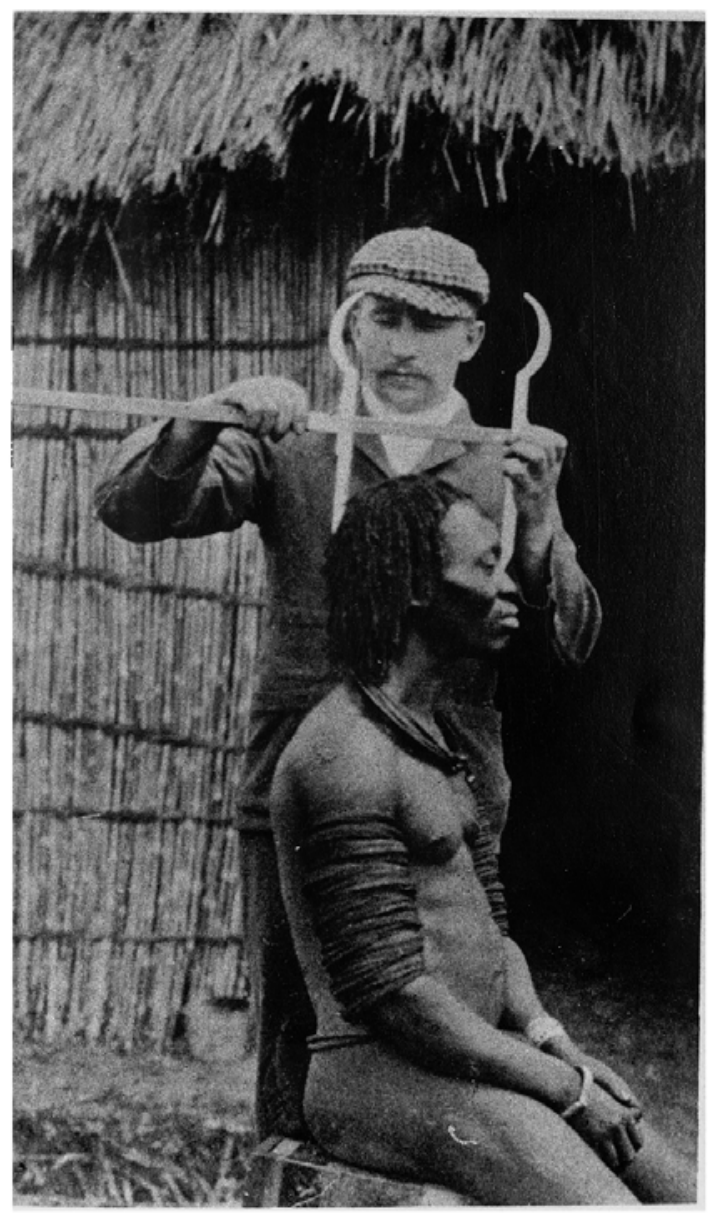

Figura 1: Fotografía de H. Johnston, 'Mr. Doggett, Naturalist on the Special Commissioner's staff Engaged in Measuring a Muamba Negro', (c.1900), H. H. Johnston The Uganda Protectorate (1902) vol. 1, p. 249.

Fuente: James R. Ryan, Photography, Geography and Empire, 1840-1914. Tesis doctoralPresentada en el Royal Holloway, University of London, 1994.

La situación o el lugar de las "razas" dentro de la historia fue un tema tratado abundantemente por los intelectuales británicos del siglo XIX. En sus observaciones sobre otros pueblos la capacidad de estos para seguir las pautas de “civilización”, era un indicador de los niveles de independencia que los “otros” podían tener. Los pueblos de África fueron vistos con el filtro de la “civilización”. En 1864, Pousey señalaba ante sus colegas de la Sociedad Antropologica de Londres, que los “negros” presentes 
Pueblos y Paisajes en la Royal Society de LondresLas ciencias humanas y el imperialismo británico

$(1860-1918)$

en la Indias Occidentales eran en general "hospitalarios, pero violentos, mal pensados y sin interés por los negocios”, a esta descripción agregaba que después de la emancipación de la esclavitud, estos “eran ignorantes de la naturaleza de los contratos”15. En resumen, el documento de Pusey, argumentaba que los las condiciones de “civilización” de los “negros” después de su emancipación dependía de las características de su “aprendizaje” (y adaptación) de la cultura y civilización occidental, particularmente anglosajona.

\section{La ocupación de los espacios}

Definido el mundo a partir de criterios de superioridad / inferioridad se desarrolló la política de expansión y ocupación de los espacios. En este contexto las formas de ver al "no europeo” fueron el argumento que justificó la imposición del orden occidental sobre pueblos y culturas no occidentales.

Este proceso iniciado unas décadas antes con la expansión de la banca, la empresas y las inversiones tanto en Europa como en el resto de los continentes se vio catalizado por la configuración del imperialismo alemán (después de la guerra franco-prusiana) y por los efectos de la crisis de 1873 que hicieron que las potencias europeas buscaran nuevos mercados y territorios alejados del proteccionismo despertado por la crisis (HOBSBAWM, 1998, p.42-53).

La búsqueda de espacios que ocupar no se limitaba solamente a una relación productiva o de inversiones, también la colonización de regiones no europeas era un tema relevante en la discusión académica. El mundo era presentando como un lugar “disponible” para los europeos. El importante demógrafo alemán E. G. Ravenstein (que entre 1855-75 trabajo en Departamento de Topografía de la Secretaría de Guerra de Gran Bretaña), postuló en 1891 la existencia de lugares apropiados para la colonización. 

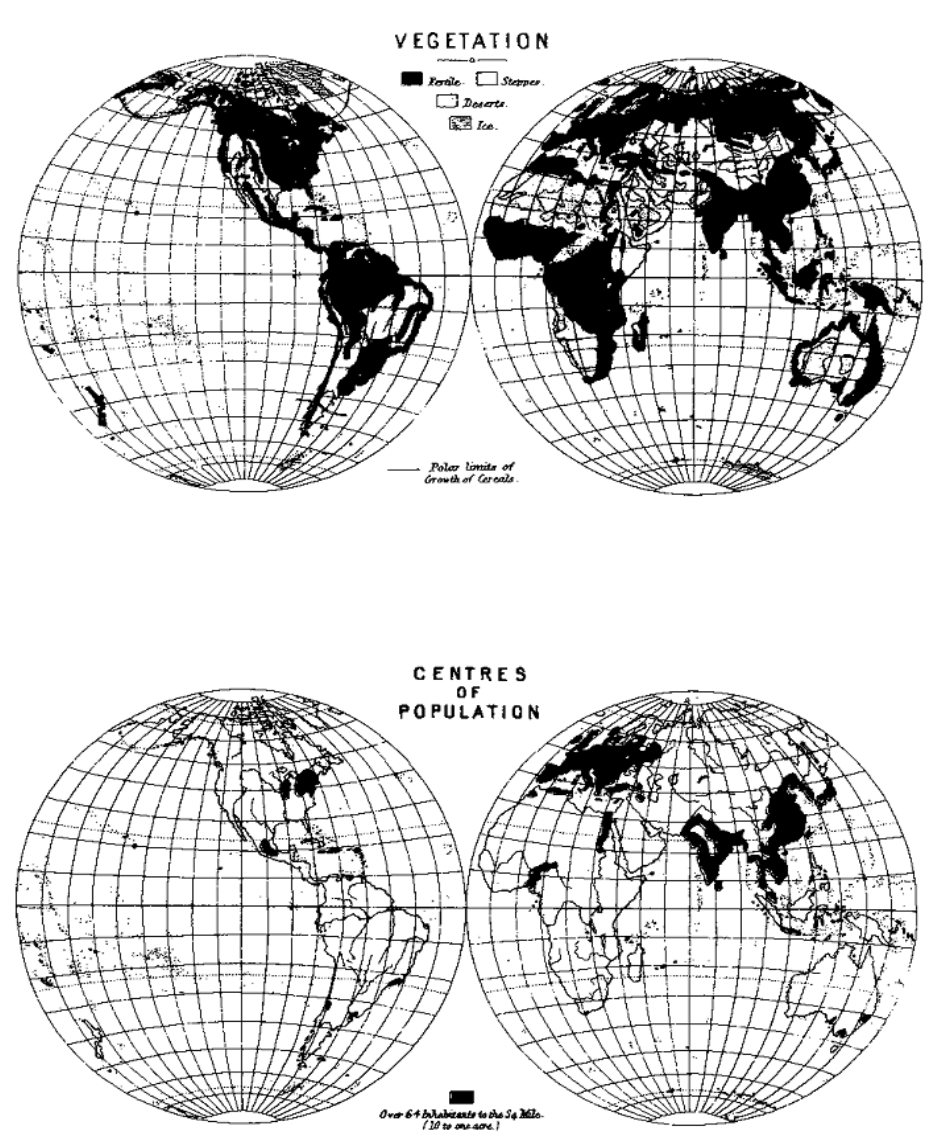

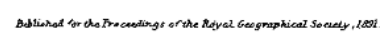

Figura 2: Mapa mundial de vegetación y población. Publicado en 1891 en trabajo de E.G. Ravenstein, “Lans of the Globe Still Available for European Settlement”.

Fuente: En: Proceedings of the Royal Geographical Society and Monthly Record of Geography, New Monthly Series. Vol. 13. N. 1 (Jan. 1891)

En su trabajo, Ravenstein establecía las condiciones necesarias para llevar adelante la colonización, además de presentar las posibilidades alimenticias de diversas regiones. Se señalaba con claridad que para que existiera una buena disponibilidad de comida los cultivos en esas zonas “disponibles” debían seguir las formas agrícolas europeas y modernas ${ }^{16}$. Por cierto en torno a las poblaciones presentes en esas zonas poco se decía, nada se encuentra sobre sus formas de subsistencia. En este punto y observado el mapa 1 (población) presentado por el geógrafo alemán vale la pena recordar las reflexiones de Harley sobre las zonas blancas, los "silencios” en la cartografía, aquellas zonas que silenciaban u ocultaban a los habitantes de esas regiones, con sus dinámicas, costumbres, etc. 
Pueblos y Paisajes en la Royal Society de LondresLas ciencias humanas y el imperialismo británico

(1860-1918)

Harley reconociendo el avance del conocimiento científico, identificó los filtros ideológicos que operan en la descripción del espacio.

\begin{abstract}
El concepto de 'silencios` en los mapas es fundamental para cualquier argumentación en torno a la influencia de sus mensajes políticos ocultos. Aquí se afirma que los mapas, al igual que los ejemplos del campo de la literatura o del mundo hablado, ejercen una influencia social tanto a través de sus omisiones como por medio de las características que describen y enfatizan [...].

También los atlas europeos, mientas codificaron un rango mucho mayor de conocimiento geográfico, promovieron una visión eurocéntrica imperialista que efectivamente reflejaba la inclinación al espacio doméstico que reforzaba la percepción europea de la superioridad cultural en el sistema mundo. Los silencios en los mapas, a menudo parte de estereotipos culturales más amplios, llegaron, por lo tanto, a poner en alto las profecías cumplidas acerca de la geografía del poder (Harley 2005, p.96-97).
\end{abstract}

La conferencia de Berlín entre noviembre de 1884 y febrero de 1885 junto a la convención Anglo-Alemana de 1898 (para repartirse los territorios lusos en África) son los episodios que evidenciaron la idea de propiedad que las potencias europeas tenían sobre los territorios no europeos en general y los africanos en particular. África no era más que una fuente de recursos.

Es difícil calcular el área de los territorios reclamados por cada país europeo. Fuera de las 11.900.000 millas cuadradas de África, probablemente la cuota de Gran Bretaña no es de menos de dos millones de millas cuadradas. Esto incluye los territorios de Níger y la región viene naturalmente bajo la esfera de la Compañía, algunos de los distritos más esperanzadores de África tropical; [...]. En Sudáfrica británica una vez más, hemos obtenido la sección de África más adaptada a la colonización europea, rica en minerales y posibilidades agrícolas ${ }^{17}$.(KELTIE, 1890, p.656).

La repartición de África representó, en el plano general la extensión de la política liberal de expropiación de tierras (Polanyi 2001, 35), a nivel planetario. Así, el liberalismo que se impuso reduciendo o acabando con las comunidades indígenas (de América) y los derechos comunitarios del campesinado europeo (Hobsbawm 1998, 197-199) desde mediados del siglo XIX, llegó a jugar un rol central en la apropiación de territorios continentales completos por parte de las potencias europeas ${ }^{18}$.

Caso particular se encuentra en América Latina ya que esta fue escenario ocupación de los territorios mediante el expediente de una forma de imperialismo informal, que se apoyaba particularmente en el prestigio que Europa tenía sobre las elites Latinoamericanas del siglo XIX, que eran capaces de aceptar una forma de subordinación a Europa (LLANOS, 2009, p. 97 - 116; CAIN y 
HOPKIN, 1980). Esto era visto como una de las causas de la atención que se le daba a África y otros continentes donde no existía una "elite blanca a la cual se le respetara”

Durante los últimos cinco años solo cuatro documentos habían sido leídos sobre Sudamérica, ante la Society, pero mientras tanto comunicaciones muy numerosas sobre África habían sido entregadas y escuchadas, a menudo atestadas de público. Él (el Presidente de la Royal Society) se preguntó a sí mismo por qué el interés de los ingleses se limitaba casi exclusivamente al continente africano. Supone que ha surgido en parte de su ser, la escena de los trabajos de misioneros como Moffat y Livingstone, cuyas aventuras y espíritus de autosacrificio han llamado la atención del país. Además de esto, el hecho de que América del Sur está en manos de gente blanca, cuyas posesiones los ingleses estaban obligados a respetar, y no en manos de personas de raza negra, cuyas posesiones no tenían el hábito de respetar, podrían haber tenido algo que ver con la diferencia en el interés que se manifiesta en los dos continentes ${ }^{19}$. (MINCHIN, 1881, p.420).

En parte importante del siglo XIX el rol jugado por la elites de los países no metropolitanos (es decir aquellos de Asía, África, América Latina implicó que estás aceptaron - en general - una suerte de asociación a las formas de “desarrollo”, “modernidad” y “progreso” surgido en las naciones industrializadas de Europa. Por cierto que en la forma en que las elites implementaron la “modernización” fue diversa ${ }^{20}$, pero aquello no niega que salvo excepciones como Japón de la restauración Meiji, la mayoría asumiera un fuerte rechazo a aquellos elementos tradicionales o aborígenes.

Durante la década de 1880 la búsqueda de mercado se transformó en un imperativo para la elite comercial y política de Londres. De esta forma surgía la "necesidad” de una política comercial nacional que consolidaba el imperialismo británico como una política del Estado (BURDETT; SMITH, 2007, p. 56-57).

En su expansión Gran Bretaña no estaba sola, otras potencias e intereses buscaban establecer niveles de poder e influencia internacional a nivel económico y político. Tal como apuntó Polanyi, el nuevo sistema mundial nacido con la industrialización había alterado las bases de la estabilidad internacional. En esta dinámica de competencia y rivalidad internacional también se involucraron sectores científicos. Los Estados nacionales establecidos contaban ya con cuerpos intelectuales comprometidos con los, en ese momento, objetivos de la nación. 
Pueblos y Paisajes en la Royal Society de LondresLas ciencias humanas y el imperialismo británico

$(1860-1918)$

\section{La Royal Society frente a la guerra}

El inicio del siglo XX no fue el mejor para Gran Bretaña, su poderío aún considerable enfrentó la guerra en Sud África y la rebelión Boxer (1900), rebeliones independistas en Irlanda y la fundación del Sinn Fein en 1905. Irlanda había llevado el problema del dominio imperial a nivel doméstico. Así el clima anterior a estallido de la Primera Guerra Mundial ya estaba enrarecido con la violencia y la movilización de hombres a la lucha. Pero aún en este escenario Gran Bretaña continuaba adelantada en lo que respecta a la distribución de su fuerza de trabajo, con sólo un 13 por ciento de su masa laboral total involucrada en la agricultura, pesca o actividad forestal, frente a un 29 por ciento en Holanda; 23 por ciento en Bélgica y un 35 por ciento en Alemania (WASSERSTEIN, 2007, p. 11).

Cuadro 4 PIB de Europa

(En porcentajes del total europeo)

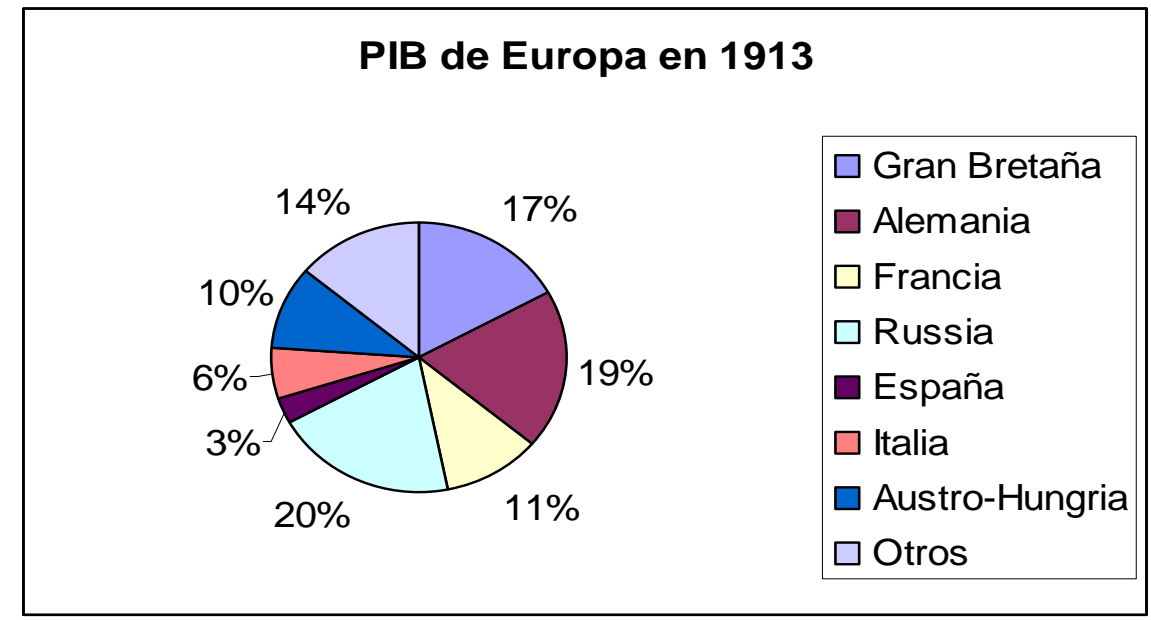

Fuente: Bairoch, Paul, “Europe’s Gross National Product, 1800-1975”. En: Journal of European Economic History. Vol. 5, N. 2, 1976, p. 282.

La defensa del poder y la ascendencia de Gran Bretaña se fundaban en la serie de rivalidades que enfrentó, particularmente debido al desarrollo de procesos de industrialización en otros países europeos. El mundo, sus productos y luego sus mercados habían entrado en una disputa. Alemania fue uno de los rivales más preocupante para los británicos. Desde la Guerra Franco Prusiana, Alemania se había constituido como potencia continental ${ }^{21}$. Las explicaciones basadas en la raza no estuvieron ausentes al momento de estalla la Primera Guerra Mundial, se intentó mostrar las tendencias "belicosas” de los Alemanes en contraste con la "mesura” de otros pueblos. 
Las Guerras del siglo XX plantearon a las potencias europeas un conjunto de problemas relacionados con el desarrollo del poder industrial-militar (HOBSBAWM, 2006). En este marco las ciencias también asumieron un rol dentro de la maquinaria del Estado, por cierto que las ciencias vinculadas a la ingeniería, la química, etc., fueron las más influenciadas por los programas de desarrollo tecnológico militar, pero esto no implicó que diversos sectores dentro de las ciencias humanas ocuparán un lugar (o pretendieran ocuparlo) dentro de las necesidades bélicas del Estado.

En lo que corresponde a un sector de la antropología y la geografía británica, la Primera Guerra Mundial fue el escenario donde las disciplinas humanas no solamente estudiaron las costumbres, culturas y espacios geográficos de otros pueblos en un marco de “superioridad” cultural que explicará y justificará el imperio, sino que se embarcaron en investigaciones que sirvieran al poder militar.

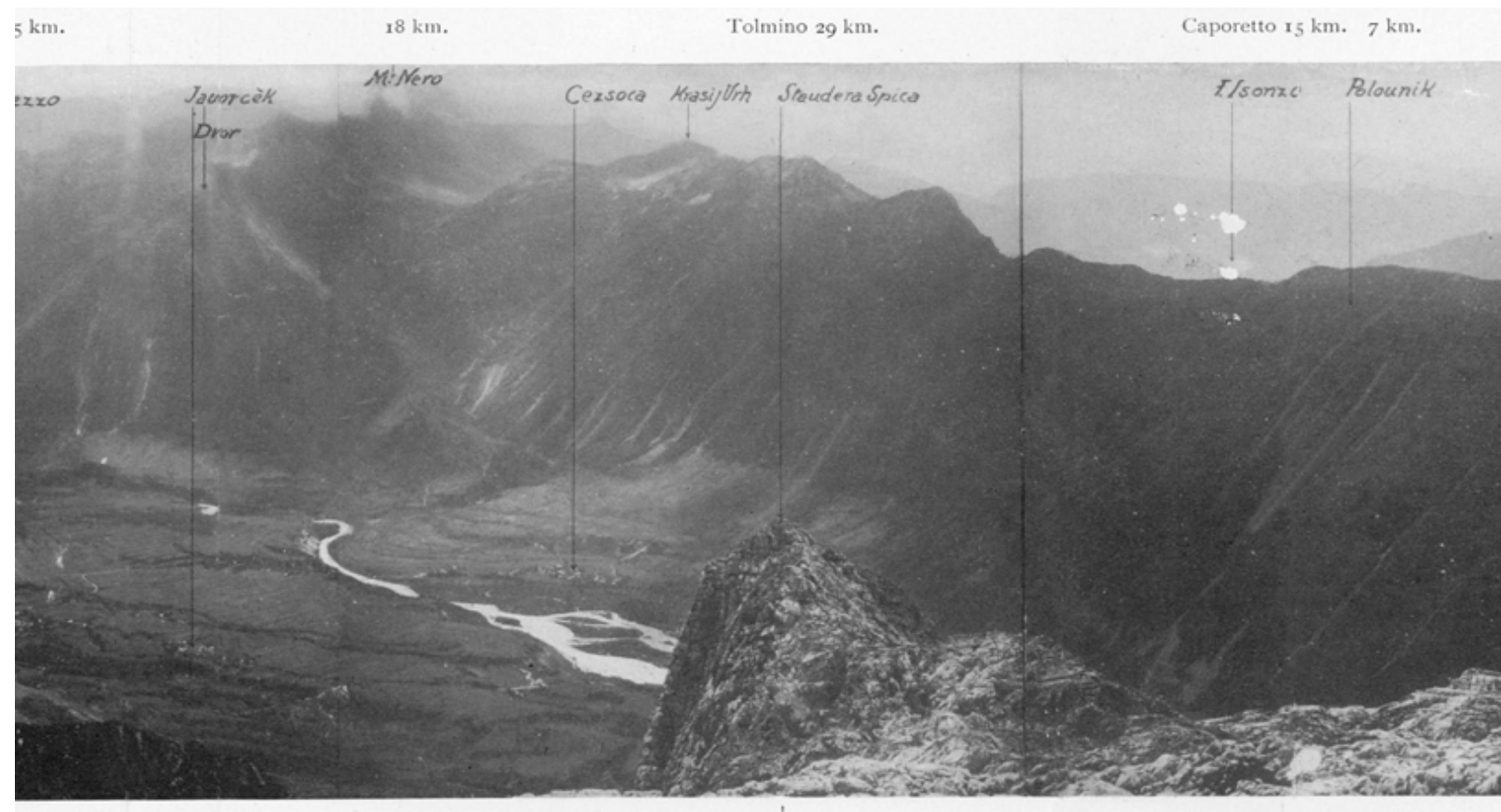

Figura 3: Fotografía del Valle de Isonzo (Italia).

Fuente: Filippi, Filippo, "The Geography of the Italian Front".

En: The Geographical Journal, Vol. 5, N.2. (Feb., 1918), 70.

La Primera Guerra mundial, fue presentada como una exigencia general a la nación británica, donde la ciencia y por ende la Royal Society debían cumplir con su parte en el sacrificio. Las tropas británicas del imperio luchaban "en cinco continentes en defensa de la libertad, la ley y la humanidad”22. En esta tarea "nacional” y “humana” fue la geografía a la luz de los documentos revisados la disciplina que asumió un mayor grado de colaboración con la campaña militar. 
Pueblos y Paisajes en la Royal Society de LondresLas ciencias humanas y el imperialismo británico

(1860-1918)

La guerra ha sido un proceso en la marcha ascendente de la humanidad, y más ahora que en cualquier momento del pasado es esencial que quienes se ven obligados a su cruel arbitrio se pongan el completo blindaje de la ciencia, su temperamento mental y sus dispositivos. En este punto [...] la geografía más que ninguna otra rama de la ciencia está adentro del arte de la guerra. Es conveniente, por lo tanto, en este período cuando todos los sujetos de la corona y ingles es llamado a considerar lo que puede hacer para su país en su hora de necesidad Suprema, que la Sociedad Real no debe sentarse y cerrar sus puertas, sino que más bien descubrir cuál es la mejor forma en que puede servir el Estado; ¿Cómo pueden utilizar sus recursos para ayudar a nuestros soldados en el campo ${ }^{23}$.(FRESHFIELD, 1915, p.2-3)

En plena conflagración también los estudios geográficos en Gran Bretaña tuvieron un desarrollo particular. Entre los diversos artículos y presentaciones de la Royal Geographical Society se evidencia la importancia del estudio de los “teatros” de la guerra en términos geográficos. En 1915 un artículo titulado "Geography of the War theatre in the Near East" daba abundantes detalles de las condiciones geográficas que debía afrontar el ejercito británico en el antiguo Imperio Turco. En este "teatro de guerra” la "defensa” imperial de la humanidad no dudaba en señalar el despojo que sufrirían las tribus que ocupaban tierras importantes para la estrategia militar. La "misión civilizadora”, el triunfo de la “civilización” sobre la “barbarie” también encontraba espacio en la contienda.

Hay algunas dificultades geográficas especiales que rigen nuestras operaciones [militares] en este ámbito. Nos estamos limitado a la vecindad inmediata de los grandes ríos del Chatt el-Arab y el Karun [...]. Sus valles superficiales se inundan en esta época del año por los deshielos [...]. Los desiertos y las marismas son recorridos o habitados por tribus poderosas. Nuestras comunicaciones, por lo tanto, tienen que ser nuestra principal preocupación, y mientras ocurren las inundaciones estas son muy difíciles de proteger. Las tribus en la orilla izquierda del Shatt y el curso inferior del Karun son, como todos los pantanos árabes, de mala fama. La tribu de Muntefik grande y bélica en la orilla derecha exige un éxito muy decisivo por nuestra parte a lo largo de la línea antes de abandonar su tierra a nuestra ocupación. (HOGARTH, 1915, p.466) 


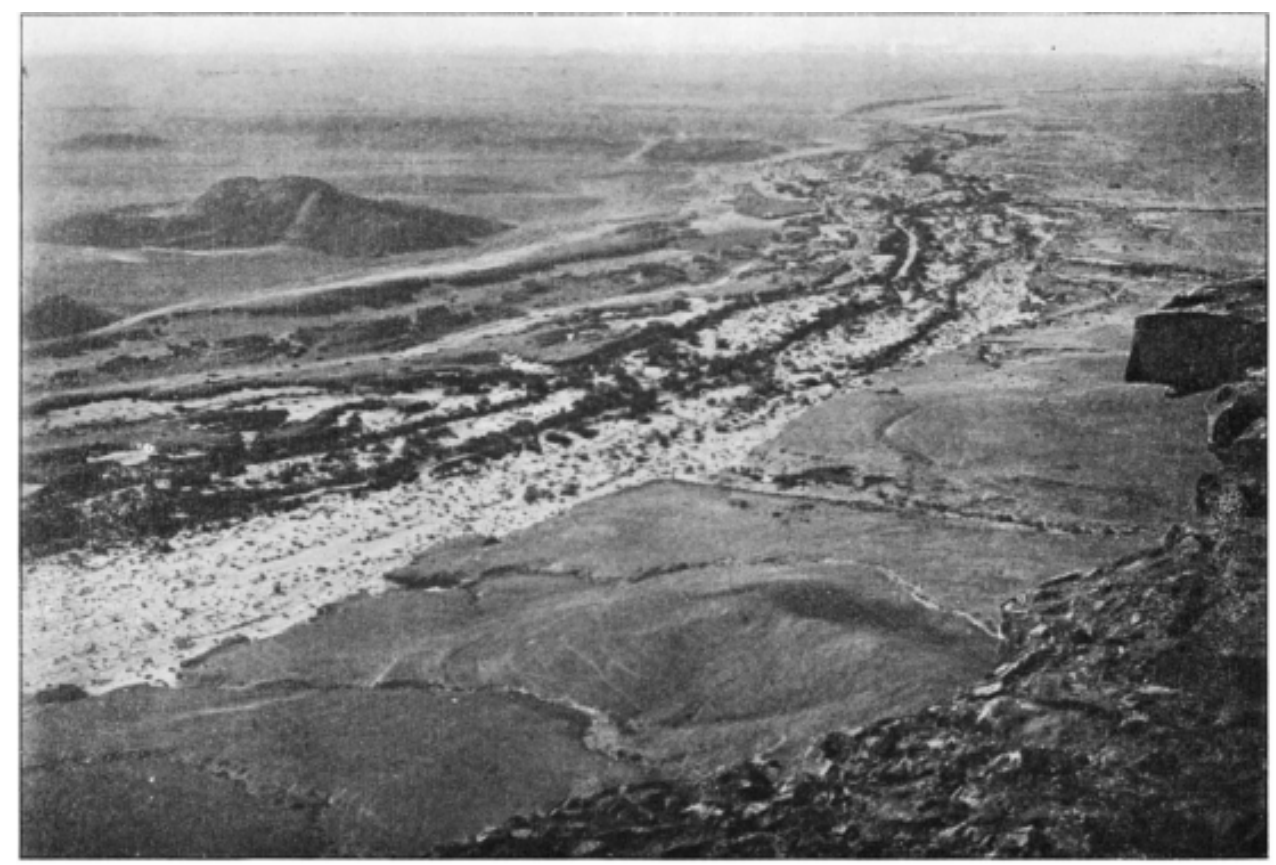

Figura 4: Fotografía área: “Antiguo camino desde Hebrón a Egipto”. Fuente: Hogarth, D.G. "Geography of the war theatre in the Near East”.

En: The Geographical Journal, Vol. 45, No. 6 (Jun., 1915), 464.

La Guerra y los prisioneros generados por la misma permitieron desarrollar estudios antropológicos que brindaron a los miembros de la Royal Society información acerca de las características “raciales” de los alemanes. En 1919 el antropólogo F. G. Parsons, estudio a los prisioneros de guerra alemanes, comparando sus cráneos, caras, color de ojos, etc., con los de soldados y funcionarios ingleses. Las conclusiones de Parsons que revelaron las diferencias entre los alemanes de diversas regiones, apuntaban a que existía una distancia "racial” importante entre los alemanes de ciertas regiones con el resto de los pueblos nórdicos (incluidos los británicos).

La tarea desplegada por los estudios antropológicos en el marco de la guerra no parece haber tenido la misma intensidad que la geografía, aún así se puede señalar que la Royal Antropological Society of London, no quiso quedarse atrás en la tarea "patriótica”. 


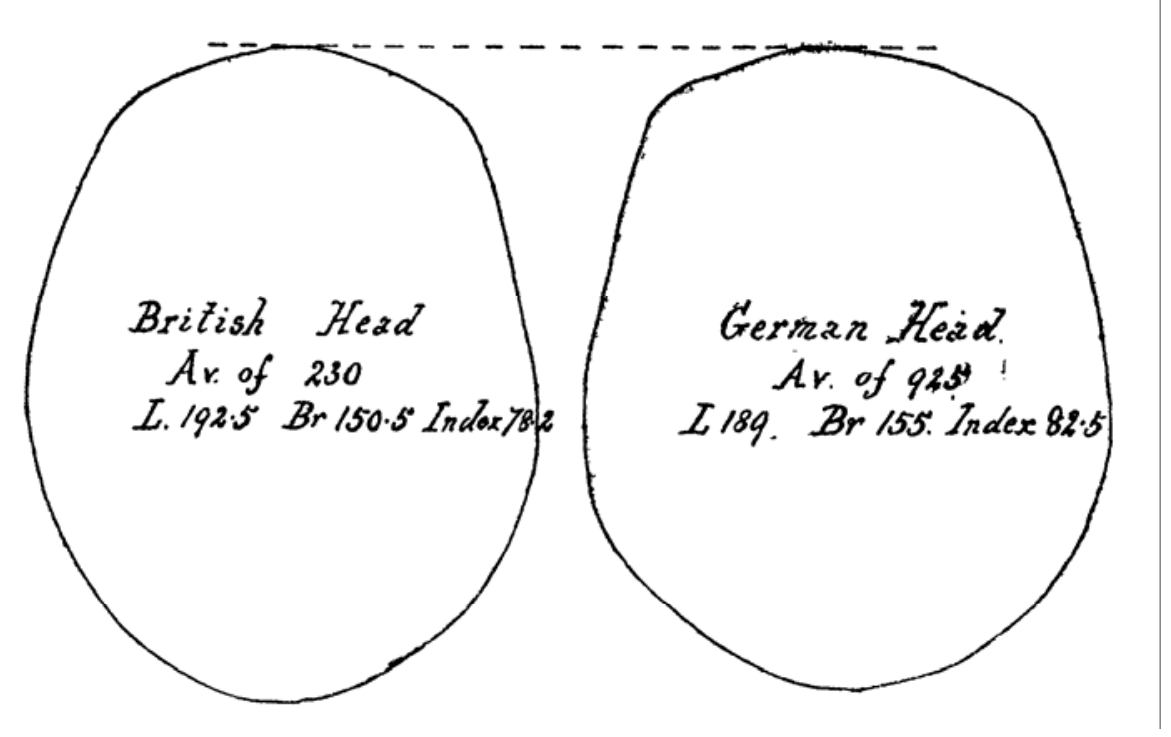

Figura 5: Medición comparativa de cráneos de soldados británicos y alemanes. Fuente: F. G. Parsons, "Anthropological Observations on German Prisoners of War”. The Journal of the Royal Anthropological Institute of Great Britain and Ireland,

En este marco el presidente de la Royal Antropological Society of London Hercules Read, informó de los aportes de la disciplina en los tiempos de guerra, agregando nociones que resaltaban la “calma y búsqueda por la soluciones ecuánimes de los ingleses, frente a la volatilidad y morbidez de otras razas” (HERCULES, 1919, p.12).

Además de lo anterior en su discurso señaló la relevancia de la antropología en el estudio de las condiciones físicas de la nación y en las medidas para el mejoramiento de estas. Con ello agregaba Read se lograban no solamente buenos soldados, sino que también buenos ciudadanos (HERCULES, 1919, p.14). En esto añadía los alemanes había adelantado a los ingleses (Idem). Así la rivalidad industrial y militar entre los Estados imperialistas se trasladaba a una supuesta capacidad físico-militar de los pueblos y las razas.

\section{Conclusión: El imperialismo como fenómeno}

En este trabajo se ha mostrado la forma que sectores de la intelectualidad de la Royal Society desarrollaron un conjunto de miradas y representaciones sobre los paisajes y culturas que funcionaban como justificación de la expansión imperial británica. 
Las representaciones sobre el otro se fundaban en la noción de "superioridad" asumida por la europeos en general y los británicos en particular. Esta "superioridad” partía de una lectura "racial” de la posición avanzada en términos económicos e industriales que Gran Bretaña tuvo durante gran parte del siglo XIX y los primeros años del siglo XX.

La Primera Guerra Mundial brindó a sectores de las ciencias humanas de la Royal Society la oportunidad de desarrollar investigaciones comprometidas con la contienda bélica que fue vista y presentada como el enfrentamiento donde Gran Bretaña “defendía la ley y la humanidad”. Defensa que declaraba abiertamente el despojo al que pueblos “tribales” serían sometidos.

El estudio del imperialismo en cuanto fenómeno histórico ha seguido una trayectoria que se ha enriquecido con los aportes de diversas disciplinas y enfoques, desde los primeros trabajos de la primera mitad del siglo XX (Hobson, Hilfering, Lenin, Gallagher, etc.), con marcado acento en lo económico se paso desde los años 1960-1970 a miradas que completaban el cuadro con perspectivas culturales que han permitido desarrollar una compresión más profunda entre las dinámicas económicas y las culturales en las que se desarrollo el imperialismo.

La relación entre ideología e imperialismo es un elemento fundamental para entender las estructuras culturales en que se desenvolvió el imperialismo y que tuvieron un importante refuerzo en las nociones desplegadas desde algunos sectores de las ciencias humanas.

El historiador norteamericano, editor de la revista History and Theory, Philip Pomper (2005) en un artículo en torno a una definición histórica de los imperios apuntó que "La administración de los imperios "viejos" también evolucionó, en cuanto las ideas liberales afectan el dominio colonial. Sin embargo algunos de los episodios más brutales de la control imperial Europea se produjeron a finales del siglo XIX y principios del XX, los antiguos imperios compitieron en nuevas áreas y "nuevas" potencias imperiales retaron a las establecidas en virtud de ideologías que dieron licencia a la esclavitud y al exterminio de los pueblos "inferiores" (POMPER, 2005, p. 3).

En el plano de las relación entre los intereses Estados modernos con el desarrollo de las ciencias se observa que desde el siglo XVII (si es que antes) se inició un proceso de especialización y relevancia de la ciencia y sus dictados dentro de la sociedad y la política, de tal fuerza que a fines del siglo XVII e inicios del XVIII en Francia la monarquía patrocinaba a un grupo de investigadores que usando el lenguaje de Newton debían validar casi teológicamente los esfuerzos de la monarquía por invalidar todo centro de poder político rival (PALLADINO y WORDBOYS, 1993, p. 95). 
Pueblos y Paisajes en la Royal Society de LondresLas ciencias humanas y el imperialismo británico

$(1860-1918)$

Para Louise Marie Pratt el siglo XVIII y puntualmente el año 1735 (con la misión científica La Condamine) marcó el momento en que las elites europeas desarrollaron su conciencia planetaria, sus ideas sobre si mismas y su relación con en el resto del mundo (PRATT, 2008, p. 16). Así, la ciencia pasó a ser capaz a los ojos del los hombres del siglo XIX y XX de medirlo todo, de explicarlo todo. En este sentido, la relación que estableció el discurso científico con intereses económicos, puede ser entendida en el marco de su consolidación como campo de poder científico, previo a procesos de autonomía del campo (BOURDIEU, 2007).

Estado imperial británico para el desarrollo de su poder requirió de especialistas que mantuvieran las diversas formas de conocimiento requeridas: se debía codificar, determinar y controlar el pasado; registrar las poblaciones, clasificar los territorios, recolectar y almacenar información y artefactos, etc. (COHN,1996, p.4-5)

Edward Said, estudiando Heart of the Darkness, identificó la naturaleza ideológica como uno de los factores centrales del imperialismo cultural, donde se piensa en establecerse en tierras que no se poseen, que son lejanas, que están habitadas y que pertenecen a otros (SAID, 2001, p. 40). Un marco ideológico ideal para la ocupación de los espacios fue la noción de superioridad racial y cultural. En este sentido el trabajo Postcolonialism de Robert Young nos brinda una amplia visión del imperialismo en su trayectoria histórico cultural y las resistencias que se han levantado desde la gran expansión europea a otros continentes el siglo XV, hasta la propuesta deconstructiva de Derrida (YOUNG, 2001).

La variedad de representaciones modernas de diverso tipo tanto etnográficas, libros de viaje, colecciones de arte se muestran asociadas a prácticas sociales y culturales que se articulan en los marcos de conocimiento y poder. En su perspectiva la representación geográfica es un expresión de conocimiento y poder (RYAN, 1994, p. 19-21).

En el plano de una organización y codificación del pasado, Saree Makdisi, en Romantic Imperialism apunta que en Inglaterra la idea de una historia mundial moderna, que dejaba otros relatos condenados a lo no histórico, al mito, etc., se dio antes de la completa configuración del imperialismo inglés. Así, el “orden” mundial dio origen a una nueva narrativa, la de homogenizar la historia, dejando fuera aquellas no modernas, ni “racionales”, previas al imperio (MAKDISI, 1998).

En un plano general Turner señala que la orientación de la ciencia en Gran Bretaña experimentó en la década de 1870 un viraje "desde los valores de la paz, cosmopolitanismo, automejora (selfimprovement), comodidades materiales, movilidad social y progreso intelectual hacia los valores de 
Claudio Llanos Reyes

colectivismo, nacionalismo, preparación militar, patriotismo, elitismo político e imperialismo social” (TURNER, 1980, p. 592).

El autor señalado ve en la etapa anterior a 1870 un periodo de buena voluntad científica y si bien eso puede ser discutible lo que si es temporalmente coincidente es que a partir de la década de 1870 la disputa por el mundo, por sus recursos y mercados se hizo más evidente y configuró el imperialismo contemporáneo (TURNER, Ídem).

\section{Notas}

${ }^{1}$ Este periodo tiene como referencias la publicación el Origen de las especies de Charles Darwin en 1859, por su importancia dentro del surgimiento del Darwinismo Social y el proceso de desarrollo y consolidación la "repartición” del mundo por las potencias europeas y la Primera Guerra Mundial.

${ }^{2}$ De mucha ayuda para este trabajo son las ideas de Pierre Bourdieu sobre campo de poder científico y desarrollo del Estado. Ver: Bourdieu, P. Intelectuales, política y poder. Editorial Eudeba: Universidad de Buenos Aires, 2007. pp. 75 170.

${ }^{3}$ Por lo anterior, este no es un estudio sobre la política imperialista británica (a nivel de Estado), ni sobre los diversos matices que el Imperialismo asumió desde, aproximadamente mediados del siglo XIX. Este tipo de temáticas y problemas sólo son tratados en la medida que nos aproximan mejor al contexto en el que las publicaciones y discusiones científicas vieron la luz.

${ }^{4}$ Esto considera los trabajos de la Sociedad de Etnología, cuya revista fue absorbida por la revista de la Sociedad Real de Antropología de Londres en las últimas décadas del siglo XIX.

${ }^{5}$ Me refiero puntualmente y exclusivamente al uso de materiales presentes en las publicaciones de las colectividades científicas británicas de la época estudiada. Las descripciones geográficas y culturales se han trabajado principalmente en base al "viaje de exploración y científico”, como en el caso de la excelente obra de Marie Luise Pratt, Imperial Eyes.

6 En este enfoque podemos señalar los trabajos de Edward Said, Marie Luise Pratt, Saree Makdisi, Robert Young y Homi Bhabha, entre muchos otros, que han llevado adelante valiosos aportes la comprensión del imperialismo y el colonialismo como fenómeno cultural

${ }^{7}$ Entre los representantes de este enfoque se puede señalar a Ngugi Thiong'o, Braj B. Kachru, Raja Rao, Bill Aschcroft, etc. Un texto recomendado para recorrer estas miradas es el de Aschcroft, Bill; Gareth Griffiths y Tiffin, Helen, The postcolonial Studies reader. London: Routledge, 1995.

${ }^{8}$ El estudio de las divergencias dentro de los campos científicos nos llevaría a terrenos interesantes, pero que nos llevarían más allá de los límites de este trabajo. De todas formas queda planteada la tarea.

${ }^{9}$ En: Napier, G. “On the Harmony between Geography and Ethnography”. En: Journal of the Anthropological Society of London, Vol. 5, (1867) p. clxxvi.

${ }^{10}$ Estos planteos no estaban libres de discusión. Un ejemplo es la discusión generada por una disertación de T.H. Huxley, en 1870, uno de los miembros de la Sociedad Real (Wallace) señaló la relación que podía existir entre las diversas "razas” y sus características “mentales”. Huxley, T.H. “On the Geographical Distribution of Chief modifications of Mandkinds”. En: The Journal of Ethnological Society of London. Vol. 2, número 4 (1870), p. 411.

11 "The most civilized races, those who live by agriculture and the arts of civilized life, all the most intellectually improved nations of Europe and Asia, have a shape of the head which differs from (...) the other forms". Dunn, R. "Some Observations on the Varying of the Human Cranium, Considered in Relation to the Outward Circumstances, Social State and Intellectual Condition of Man”. En: The Journal of Ethnological Society of London, Vol. 4 (1856), p. 41.

${ }^{12}$ Sobre los sucesos de Perterloo Lord Liverpool (1819) declaraba en el parlamento que "un estallido en Londres y todo está perdido".

${ }^{13}$ Nappier, G. "Table of Human Races, Classed in Accordance with the Moral and Intellectual Characteristics”. En: Anthropological Society of London, Vol. 5, 1867.

${ }^{14}$ Necesario es apuntar que el problema no está en la reacción, más o menos comprensible, frente a lo desconocido, sino que en que a partir esta de diferencia o considerándola se constituyó una representación de inferioridad. 
Pueblos y Paisajes en la Royal Society de LondresLas ciencias humanas y el imperialismo británico

$(1860-1918)$

\footnotetext{
${ }^{15}$ Pusey, Bouverie, “The Negro in Relation to Civil Society”. En Journal of the Anthropological Society of London, Vol 2 1864. CCLXXVI-CCLXXVII.

16 E.G. Ravenstein, "Lans of the Globe Still Available for European Settlement". En: Proceedings of the Royal Geographical Society and Monthly Record of Geography, New Monthly Series. Vol. 13. N. 1 (Jan. 1891), p. 27-35.

${ }^{17}$ Keltie, J. Scott, "The partition of Africa” (1890). En: Proceddings of the Royal Geographical Society and Monthly Records of Geography, New Monthly Series. Vol. 12, número 11 (noviembre 1890), p. 656.

${ }^{18}$ Este fenómeno, de concentración de la propiedad de la tierra no se restringió solamente a las zonas extraeuropeas, pues hacia la década de 1870 unas 7.400 personas poseía casi la mitad de las tierras de Inglaterra. Ver: Deane, Phyllis, $L a$ primera revolución industrial. Barcelona: Península, 1998. pp. 297 ss.

${ }_{19}$ Minchin, J. B. Eastern Bolivia and the Gran Chaco. En Proceddings of the Royal Geographical Society and Monthly Records of Geography, New Monthly Series, Vol. 3, No. 7. (Julio, 1881), p. 420.

${ }^{20}$ Esto lo observa Hobsbawm particularmente para el periodo de descolonización (Hobsbawm, Eric, Historia del Siglo XX. Buenos Aires: Crítica, 2006. pp. 205 -207.) Pero es también aplicable para la situación que enfrentaron las elites latinoamericanas durante el siglo XIX.

${ }^{21}$ En los datos presentes en el cuadro número 4 se debe considerar que Gran Bretaña a pesar de la competencia de los otros estados seguía siendo uno de los principales exportadores industriales del mundo y el principal centro financiero de éste. Alemania era de las potencias rivales la más industrializada pues Rusia con una población cercana a los 150 millones de habitantes mantenía un estructura profundamente agrícola.

22 Douglas W. Freshfield, (Presidente de la Sociedad Real de Geógrafos), “Address At The Anniversary General Meeting, May 17, 1915”. En The Geographical Journal, Vol. 46, No. 1 (Jul., 1915), B.

${ }^{23}$ Douglas W. Freshfield, (Presidente de la Sociedad Real de Geógrafos), “Address At The Anniversary General Meeting, May 17, 1915”. En The Geographical Journal, Vol. 46, No. 1 (Jul., 1915), 2-3.
}

\section{REFERÊNCIAS}

ASCHCROFT, B.; GRIFFITHS, G.; TIFFIN, H.; The post-colonial Studies reader. London: Routledge, 1995.

BAIROCH, P., “Europe's Gross National Product, 1800-1975”. En: Journal of European Economic History. 1976 v. 5, no 2.

BURDETT SMITH, S. British nationalism, Imperialism and the City of London (1880 - 1900) .Tesis doctoral , Queen Mery College, University of London.

BOURDIEU, P. Intelectuales, política y poder. Editorial Eudeba: Universidad de Buenos Aires. 2007.

COHN, B. Colonialism and its formo f Knowledge. The British in India. Princeton: Princeton University Press. 1996.

FISHER, J.; PRIEGO, N. Ignorance and 'Habitus': Blinkered and Enlightened Approaches Towards the History of Science in Latin America, Bulletin of La tin American Re search, 2006, v. 25, nº 4.

FREEDEN, M. 1976 Biological and Evolutionary Roots of the New Liberalism in England. En: Political Theory, v. 4, $\mathrm{n}^{\circ} .4$.

FRESHFIELD, D. W., (Presidente de la Sociedad Real de Geógrafos), Address At The Anniversary General Meeting, vMay 17, 1915. En The Geographical Journal, Vol. 46, No. 1 (Jul., 1915), 2-3. 
FONTANA, J. Europa ante el espejo. Crítica: Barcelona. 2000

GALLAGHER, J.; ROBINSON, R. () “The Imperialism of Free Trade”. En: The Economic History Review, New Series, 1953, v. 6, n 1, p. 1-15.

KELTIE, J. Scott, The partition of Africa (1890). En: Proceddings of the Royal Geographical Society and Monthly Records of Geography, New Monthly Series. Vol. 12, número 11 (noviembre 1890), p. 656.

HARLEY, J.B. La Nueva Naturaleza de los Mapas. Esayos sobre la historia de la cartografía. México: Fondo de Cultura Económica. 2005.

HOBSBAWM, E. La Era del Imperio. Crítica: Buenos Aires. 1998.

HOBSBAWM, E. Historia del Siglo XX. Buenos Aires: Crítica. 2006.

HOGARTH, D.G. Geography of the war theatre in the Near East. En: The Geographical Journal, Vol. 45, No. 6 (Jun., 1915), (457-467), p. 466.

LLANOS, C. Apuntes en torno a las representaciones de la modernidad capitalista. En: Utopía y Praxis Latinoamericana. Universidad de Zulia, Venezuela. 2009, Año 14, nº 45.

MAKDISI, S. Romantic Imperialism. Cambridge Press: Londres. 1998.

NEWSOME, D. El mundo según los victorianos. Editorial Andrés Bello: Santiago. 2001.

READ, H. Presidential Address. Anthropology and War. En: The Journal of the Royal Anthropological Institute of Great Britain and Ireland, Vol. 49 (Jan. - Jun., 1919), p. 12.

ROUSSEAU, G. S. Science and the Discovery of the Imagination in the Enlightened England. En: Eighteenth - Century Studies, 1969, v. 3, n 1.

RYAN, J. R, Photography, Geography and Empire, 1840-1914. Tesis doctoral presentada en el Royal Holloway, University of London. 1994.

PALLADINO, P.; WORBOYS, M. Science and Imperialism. En: ISIS vol. 94, marzo. 1993.

PRATT, M. L. Imperial Eyes. Nueva York: Routledge. 2008.

POLANYI, K. The Great Transformation. Boston: Beacon Press, 2001.

POMPER, P. The History and Theory of Empires. En: History and Theory, Theme Issue 44:

Theorizing Empire. Dec., 2005. p. 1-27. v. 44, $\mathrm{n}^{\circ} .4$

SAID, E. Cultura e Imperialismo, Crítica: Barcelona. 2001.

SMITH, B. Europe in the Contemporary World. 1900 to the Present. Boston: Bedford/St. Martin's. 2007. 
Pueblos y Paisajes en la Royal Society de LondresLas ciencias humanas y el imperialismo británico (1860-1918)

THOMPSON, E. Thompson Esencial. Crítica: Barcelona. 2001.

TURNER, F. Public Sciences in Britain 1880 - 1819. En: ISIS, Diciembre, 1980 v. 71

WASSERSTEIN, B. Barbarism and Civilization, 2007.

YOUNG, Robert. Postcolonialism. Oxford: Blackwell. 2001.

\section{Fuentes}

Anthropological Society of London

Proceedings of the Royal Geographical Society and Monthly Records of Geography, New Monthly Series

Journal of the Anthropological Society of London

The Journal of Ethnological Society of London

Transactions of the Ethnological Society of London

The Geographical Journal

Recebido em 27/10/2010

Aprovado em 09/02/2011 